\title{
Evaluation of an open-rota system in a Danish psychiatric hospital: a mechanism for improving job satisfaction and work-life balance
}

\author{
JOANNA PRYCE MS c , P h D , CP s y c h o l ${ }^{1}$, KAREN ALBERTSEN MA, PhD ${ }^{2}$ \\ and KARINA NIELSEN M S c , P h D 3 \\ ${ }^{1}$ Lecturer, Occupational Psychology, Goldsmiths College, University of London, London, UK, 2Senior \\ Researcher, The National Institute of Occupational Health, Copenhagen, Denmark and ${ }^{3}$ Researcher, The \\ National Institute of Occupational Health, Copenhagen, Denmark \\ Correspondence \\ Joanna Pryce \\ Psychology Department \\ Goldsmiths College \\ University of London \\ New Cross SE14 6NW \\ London \\ $U K$ \\ E-mail:j.pryce@gold.ac.uk
}

Aims To evaluate the impact of an open-rota scheduling system on the health, work-life balance and job satisfaction of nurses working in a psychiatric ward in Denmark.

Background The effects of shift rotation and scheduling are well known; however, little is known about the wider benefits of open-rota systems.

Method A structured questionnaire was distributed to control and intervention groups preintervention and postintervention (20 months). Nurses within the intervention group trialed an open-rota system in which nurses designed their own work-rest schedules.

Results Nurses in the intervention group reported that they were more satisfied with their work hours, less likely to swap their shift when working within the open-rota system and reported significant increases in work-life balance, job satisfaction, social support and community spirit when compared with nurses in the control groups.

Conclusions The ownership and choice over work-rest schedules has benefits for nurses, and potentially the hospital.

Keywords: intervention, job satisfaction, scheduling, work-life balance, working hours 


\section{Introduction}

The demands that work schedules place on nurses has been an area of interest within the health care setting (Wilson 2002, Gieger-Brown et al. 2004). Shiftwork, and in particular night work and shift rotation, has been found to impact on a range of health outcomes (Harrington 1994, Spurgeon \& Cooper 2000). Whilst research has informed the development of shift rotation and scheduling strategies, little is known about the effect of open-rota systems and the potential benefits these may have for individuals and their health. This study presents the results of an open-rota scheduling system introduced in a Danish psychiatric hospital. The study draws from a participatory approach whereby participating nurses were involved in every stage of the intervention design, implementation and evaluation. The project aimed to benefit the health, well being, job satisfaction and work-life balance of nursing staff.

\section{The impact of working hours and work scheduling on health and well being}

Inadequate work scheduling and long working hours have been identified as a major threat to employee health and well being. A report by the European Commission (1998) indicated that up to $72 \%$ of the workforce studied reported that working long hours impaired their home life and relationships. The relationship between working hours and a range of health outcomes has been well documented. For example, long working hours have been associated with a rise in stress levels (Maruyama \& Morimoto 1996, Weinberg et al. 1999); increases in reported anxiety; insomnia and somatic symptoms (Houston \& Allt 1997) and mental health (Ezoe \& Morimoto 1994). Similarly, shiftwork has also been found to bring about serious threats to health and productivity (Hughes 2004). Employees working shifts have been found to suffer from fatigue; sleep disruptions; impaired concentration; irritability and somatic symptoms such as digestive problems (Spurgeon et al. 1997, Scott 2000). However, studies have suggested that the effects of shiftwork can be reduced not only through adopting appropriate shift rotations (Harrington 1994) but also through increasing the predictability of work schedules (Costa et al. 1989) and choice over shift pattern (Barton et al. 1993).

\section{Role of choice}

The degree of choice over work schedules has been identified as a key issue in the relationship between working and health. Giving employees a degree of choice over their shift system has been found to mediate the perceived acceptability of the shift (Barton et al. 1993). In a longitudinal study conducted by Stevens et al. (2000) employees who chose to work in excess of their hours typically worked longer hours, were significantly less stressed and took less sick leave than their coerced counterparts. Stevens et al. (2000) concluded that the implications for ill health were significantly increased when employees were coerced into working more than 5 hours of overtime a week consistently. In summary, working long, unsociable and unpredictable hours has been found to have a negative impact on health and well being. One reason for this may be the impact that work and work scheduling has on an individuals' home life. The extent to which employees feel they can balance their work and home lives has been found to affect a range of health and organizational outcomes: necessarily, much of this research has focused upon working hours and work scheduling.

\section{The role and importance of work-life balance}

The benefits of achieving a balance between work and home lives for employees are widely recognized in terms of enhanced job satisfaction, well being and health (Cooper \& Lewis 1998), whilst the direct gains to business of supporting work-life balance initiatives are increasingly recognized by organizations (Dex \& Scheibl 1999, Goff et al. 1990). Despite evidence of widespread efforts to address work-life balance through a range of organizational initiatives (e.g. Department of Trade and Industry 2004), recent employee surveys suggest that many people 
still face great difficulties balancing work and family responsibilities. The effects of this slow implementation of a balanced culture are potentially huge.

Understanding and managing the balance between the work-family interface is of growing importance for employers, individuals and researchers. Competing demands between work and personal roles often result in conflict for employees (Grant-Vallone \& Donaldson 2001). The spillover effects from work to home environments have been widely documented (Burke \& McKeen 1992, Jones \& Fletcher 1996, Grzywacz \& Marks 1999) and can be seen in the deterioration of the quality of partner- and parent-roles because of work-related stress (Langan-Fox 1998) and the impairment of social and non-work interests because of the difficulties in securing a regular work-leisure patterns (Maruyuma et al. 1995). Such findings parallel those highlighted within the shiftwork literature where employees working unsociable shifts and long hours have been consistently found to suffer from increased social isolation and impaired interpersonal relationships (Harrington 1994).

With a growing body of evidence to support the need for a balanced approach to work and life, there is an increasing need to identify effective interventions. However, research efforts have largely focused on developing an understanding of the antecedents and outcomes of work-life conflict (Baltes \& Heydens- Gahir 2003). Less attention has been focused on the effectiveness of interventions to enhance work-life balance and individual and organizational health. In practice, a range of interventions has been put in place in organizations including cultural change, home working or flexible working. However, in organizations where such approaches are more difficult to employ - such as nursing and health care settings - interventions have focused on working hours and work scheduling. This study presents the findings of an evaluation of an openrota work scheduling intervention.

The aims of this study were: to assess the impact of an open-rota scheduling system on health, job satisfaction and work-life balance and to evaluate the processes involved in the uptake of the intervention, the maintenance of the intervention in order to guide the implementation of openrota systems.

\section{Method}

\section{Participants and procedure}

Eight nursing teams volunteered to participate in this study. Four nursing teams were assigned to a control group $(n=91)$ and four teams to intervention groups $(n=86)$. The participants were nurses $(60 \%)$ and health care workers (40\%) working together in multidisciplinary teams. Participants were predominantly female (92\%) and the average age within the teams was 43 years. The attrition rate was low ( $5 \%$ and $7 \%$ in the control and intervention groups respectively).

Participating teams were recruited from a psychiatric hospital in Denmark as part of a hospitalwide project to enhance work and well being. This project was one of five projects that the teams had available throughout the 20 months. The teams were assigned to the control and intervention groups at random. The teams within the intervention group were invited to attend a 1day workshop in which case studies of work scheduling interventions were presented. The intervention groups were then asked to develop an intervention appropriate for their team, implement it and manage the chosen intervention for a period of 20 months. Participants in both the control and intervention groups were invited to complete a questionnaire survey at the start of the study and 20 months following. The questionnaire data were analysed using MANOVA repeated measures analysis.

An evaluation of the processes involved in developing, implementing and maintaining the intervention was also conducted to capture information not included within the questionnaire. This component of the evaluation comprised the recording of ongoing discussions between the 
researcher and the teams and a series of interviews at the end of the project to identify barriers and facilitators to the process. The recorded notes were then reviewed for themes and key-learning points throughout the intervention process were extracted.

\section{Measures}

A questionnaire survey was designed and distributed to all participants (control and intervention groups) at the start of the study and 20 months following. The questionnaire included demographic measures, measures of work organization and health outcome measures. These included:

\section{Work scheduling indices}

The following variables were tailored to this study and measured different aspects of work scheduling: 'What are your usual working hours'? (day/evening/night/ rotating); 'Do you influence the planning of your work schedule' (always to almost never); 'Do you usually work Saturdays and Sundays over a 4-week period'? (yes/no); 'How do you feel about working weekends'? (very satisfied to very dissatisfied); 'How often do you swap shifts' (1-4 times per month to never); 'When you and your colleagues swap shifts, how quickly can it be arranged'? (the same day to a month or more before); 'How do the charge nurse react when a shift is swapped'? (does not know/is positive/doesn't care/is negative, but accepts/is negative and tries to prevent it).

\section{Work-life balance indices}

Five single-item measures of 'work-life balance' were developed for use in this study: 'Do you have the energy to be with your friends and family in your time off? (always to almost never); 'Would it be easier for you to balance your work and private/family life if your work schedule was more flexible'? and 'Do you feel you spend so much energy on your work that it impairs your family/private life'? (yes to not at all); 'I have enough time for my family/private life' (totally suitable to not suitable); 'Do you experience conflict between your work and family/private life so that you had to be in two places at once'? (often to never).

\section{Health and well-being indices}

'Global self-rated health' was measured by a single item: 'How do you rate your health in general'? (very good to very poor; Borg \& Kristensen 2000). 'Stress symptoms' were measured by three scales, each consisting of four-items (Setterlind \& Larsson 1995): behavioural symptoms (time $1 \alpha$ $=0.81$; time $2 \alpha=0.85$ ); cognitive symptoms (time $1 \alpha=0.87$; time $2 \alpha=0.91$ ) and somatic symptoms (time $1 \alpha=0.67$; time $2 \alpha=0.58$ ). 'Vitality' was measured with four-items developed by Setterlind and Larsson (1995) (time $1 \alpha=0.60$; time $2 \alpha=0.63$ ).

'Job satisfaction' was measured by a five-item scale with the response categories (very satisfied to very dissatisfied; time $1 \alpha=0.58$; time $2 \alpha=0.69$ ). 'Social support' was measured by a four-item scale (time $1 \alpha=0.78$; time $2 \alpha=0.74$ ). Finally, a measure of 'Sense of Community' was included with a three-item scale (time $1 \alpha=0.79$; time $2 \alpha=0.71$ ). All three scales were taken from the Copenhagen Psychosocial Questionnaire (Kristensen \& Borg 1998).

\section{Interventions}

This study presents an evaluation of a work scheduling intervention developed to improve work scheduling with the broader aim of increasing employee influence, job satisfaction and experience of work-life balance. The interventions were implemented as part of a 'Women at work' project funded by the Danish Ministry of Employment. 
Each of the four intervention groups formed a steering committee composed of safety, trade union and project representatives, which was supported by a larger project group of between 5 and 7 employees and two external consultants. To encourage ownership of, and thereby secure commitment to, interventions the consultants adopted a participatory approach as recommended by Jeppesen (2003). Here, consultants invited steering groups to a workshop during which case studies of interventions were presented and discussed. Steering groups, in collaboration with the wider project teams, identified an appropriate work scheduling intervention to be implemented in their team. Surprising by their similarity in approach, three of the four intervention groups agreed to implement an open-rota system. Within this system employees was asked to schedule their shift preferences into an open (uncompleted) rota. When doing so, they were asked to do complete this responsibly and fairly, e.g. to consider the needs and preferences of others and the relief required in other departments. One or two employees then had the responsibility to finetune the plan, and this responsibility was rotated each week between the staff. This intervention constituted the most concrete change in the work environment over the study period. One of the four intervention groups decided not to go ahead with the open-rota system. Because of work pressures they decided that they would prefer to see the outcomes of the other trial teams before proceeding. Only the three of the intervention groups that implemented this open-rota system are included in the analyses in this study. There were no significant differences found between the team that dropped out of the intervention group and the control group on any of the outcome variables.

\section{Results}

Three of the intervention groups decided to trial an open-rota system whereby employees designed their own work-rest schedule. Employees reported that they were more satisfied with their work hours and were less likely to swap their shift when working within the openrota system. Furthermore, they reported a significant increase in work-life balance under this system.

To examine whether the interventions led to improved health and well-being outcomes, we conducted a repeated measures multivariate analysis of variance (MANOVA). All dependent variables were included, with intervention group as the between-subjects variable and time as the within-subject variable. Whilst the aggregate analyses were nonsignificant (Wilks Lambda $=0.95$, $F(8,84)=0.56, P>0.05)$, further univariate analyses suggested that the effects of the work-life balance interventions on health were diffuse across the health outcomes measured. These are shown in Table 1.

A significant difference between time 1 and time 2 was reported in the intervention group over and above changes within the control group in four key areas including job satisfaction and worklife balance $[F(173)=1.88, P<0.01$ and $F(175)=3.18, P<0.01$ respectively $]$ and social support and sense of community $[F(174)=4.05, P<0.01$ and $F(176)=4.44, P<0.001$ respectively]. Further trends were identified in measures of vitality and somatic symptoms; however, these were non-significant.

\section{Process evaluation of the interventions}

In addition to the formative evaluation presented above, the researchers evaluated the processes involved in developing, implementing and maintaining the intervention to provide context to the findings and inform future interventions. Preliminary investigations indicated that the employees were frustrated with the changes and doubted that the intervention would have an impact. However, at the midpoint and close of the project, there was high agreement within the teams that it had been a fruitful process that encouraged important discussions about the daily work, resulting in higher levels of energy and satisfaction within the groups. The employees noted that the open-rota intervention not only saved time, but also provided them with an insight into 
how the department operated; greater influence and greater satisfaction. However, the intervention was not received without problems: some participants reported that they experienced competition in being the first to allocate their preferred shifts, whilst others reported that they felt insecure and uncomfortable with the increased responsibility of the finetuning of the rota. The consultants and the project manager indicated that the open-rota had contributed to an improved insight into the availability and utilization of resources, for example, the costs of absence; the rationale behind task allocation and the importance of maintaining the quality of work. Furthermore, team members reported that the open-rota had increased the level of team awareness within the groups. Combining these process- based evaluations, the overall perception was that the new approach to work scheduling took account of individual, group and organizational needs and constraints.

\section{Discussion}

This study builds on previous research to highlight the benefits of an open-rota scheduling system. It presents new research and explores the effect of the implementation of open-rota scheduling systems on a wide range of physical, social and psychological health outcomes. The findings suggest that open-rota systems are, to some extent, an effective intervention to enhance job satisfaction, work-life balance, support and cooperation within nursing teams. In this study, no significant benefits to health and well being as measured by general health, somatic, behavioural or cognitive symptoms or vitality, were found. However, it is widely recognized that such benefits are difficult to capture in intervention studies of this nature (Kompier 2004).

The data collected from the process evaluation indicated that whilst there was initial resistance to interventions, they were largely positively received and participants found the process a valuable entry into a broader discussion about the way in which work is designed and managed. The process evaluation allowed the authors to identify key-learning points that may facilitate others in the implementation of open-rota systems. These are summarized in Table 2.

This study highlights some of the benefits of open-rota systems; however, this form of intervention study is not without its limitations (Ball \& Pike 2003). First, there are a great many other factors that are likely to have influenced the health and well being of the nurses and care workers over the 20-month period, which were not included in this study. However, it is likely that the intervention did have an effect as is reflected in changes in immediate working conditions (social support and sense of community) and work-life balance. Secondly, whilst superordinate group (control and intervention) level data provides a clear overview of effect, a further group level analysis indicated that benefits to general health were accrued to one of the three intervention groups over this period. If we are to better understand the true impact of open-rota scheduling interventions there is need to employ multimethod longitudinal studies. In doing so, and detailing the processes through which the interventions were designed, implemented and maintained, we will be able to extrapolate and share learning effectively.

\section{Conclusions}

In conclusion, this study indicates that open-rota scheduling systems, and the ownership and choice over work-rest schedules they afford, have significant benefits for nurses. Nurses in the intervention group reported that they were more satisfied with their work hours, less likely to swap their shift when working within the open-rota system and reported a significant increase in work-life balance, job satisfaction, social support and ratings of community spirit when compared with nurses in the control groups. Furthermore, this study aimed to share the learning of the implementation process, demonstrating that increments to quality of work 'can' be achieved without substantive investment of financial and personnel resources. 


\section{Acknowledgements}

The findings reported are drawn from the 'Women at work' project conducted at The National Institute of Occupational Health, Denmark. This research was funded by the Danish Ministry of Employment.

\section{References}

Ball J. \& Pike G. (2003) Stepping Stones: Careers of Nurses in 2003. Results from the RCN Employment Survey 2003. Employment Research Ltd, London.

Baltes B.B. \& Heydens-Gahir H.A. (2003) Reduction of workfamily conflict through the use of selection, optimisation and compensation behaviours. Journal of Applied Psychology 88 (6), $1005^{-1018 .}$

Barton J., Smith L., Totterdell P., Spelten E. \& Folkard S. (1993) Does individual choice determine shift system acceptability? Ergonomics 36 (1-3), 93-99.

Borg V. \& Kristensen T.S. (2000) Social class and self-rated health: can the gradient be explained by differences in life style and work environment? Social Science Medicine 51, 1019-1030.

Burke R.J. \& McKeen C.A. (1992) Women in management. In International Review of Industrial and Organizational Psychology, Vol. 7 (C.L. Cooper \& I.T. Robertson eds), pp. 245- 283. John Wiley \& Sons, London, UK.

Cooper C.L. \& Lewis S. (1998) Managing your Career, Family and Life. Kogan Page, London.

Costa G., Lievore F., Casaletti G. et al. (1989) Circadian characteristics influencing interindividual differences in tolerance and adjustment to shiftwork. Ergonomics 32 (4), 373-385.

Department of Trade and Industry (2004) Work-life Balance Campaign. Available at: http://www.dti.gov.uk/er/workand family.htm

Dex S. \& Scheibl F. (1999) Business performance and familyfriendly policies. Journal of General Management 24 (4), 22- 37.

European Commission (1998) Working Time: Research and Developments 1995-1997. Employment and Social Affairs: Industrial Relations and Industrial Change. European Commission, Belgium.

Ezoe S. \& Morimoto K. (1994) Behavioural lifestyle and mental health status of Japanese factor workers. Preventive Medicine 23, 98-105.

Gieger-Brown J., Muntaner C., Lipscomb J. \& Trinkoff A. (2004) Demanding work schedules and mental health in nursing assistants working in nursing homes. Work and Stress 18 (4), 292-304.

Goff S.J., Mount M.K. \& Jamison R.L. (1990) Employer supported child care, work-family conflict and absenteeism: a field study. Personnel Psychology 43, 793-809.

Grant-Vallone E.J. \& Donaldson S.I. (2001) Consequences of work-family conflict on employee well-being over time. Work and Stress 15 (3), 214-226.

Grzywacz J.G. \& Marks N.F. (1999) Reconceptualizing the work-family interface: An ecological perspective on the correlates of positive and negative spillover between work and family. Journal of Occupational Health Psychology 5 (1), 111- 126.

Harrington J.M. (1994) Shiftwork and health: a critical review of the literature on working hours. Annals of the Academy of Medicine, Singapore 23, 699-705. 
Houston D.M. \& Allt S.K. (1997) Psychological distress and error making among junior house officers. British Journal of Health Psychology 2 (2), 141-151.

Hughes D. (2004) The perils of shiftwork. American Journal of Nursing 104 (9), 60-63.

Jeppesen H.J. (2003) Participatory approaches to strategy and research in shiftwork interventions. Theoretical Issues in Ergonomics Research 4, 289-301.

Jones F. \& Fletcher B.C. (1996) Taking work home: a study on daily fluctuations in work stressors, effects on moods and impacts on marital partners. Journal of Occupational and Organizational Psychology 69, 89106.

Kompier M. (2004) Research Priorities in Occupational Health Psychology. Proceedings of the European Academy of Occupational Health Psychology, Instituto superior da maia, Oporto, Portugal.

Kristensen T. \& Borg W. (1998) Copenhagen Psychosocial Questionnaire (COPSOQ). A Questionnaire on Psychosocial Working Conditions, Health and Well-being in three Versions. The Psychosocial Department, National Institute of Occupational Health, Copenhagen, Denmark.

Langan-Fox J. (1998) Women's career and occupational stress. In International Review of Industrial and Occupational Psychology, Vol. 13 (C.L. Cooper \& I.T. Robertson eds), pp. 273304. John Wiley and Sons, London, UK.

Maruyuma S., Kohno K. \& Morimoto K. (1995) A study of preventative medicine in relation to mental health among middle management employees: Part 2. Effects of long working hours on lifestyles, perceived stress and working life satisfaction among white collar middle management employees. Japanese Journal of Hygiene 50, 849-860.

Maruyama S. \& Morimoto K. (1996) Effects of long work hours on life-style, stress and quality of life among intermediate Japanese managers. Scandinavian Journal of Work, Environment and Health 22 (5), 353-359.

Scott A. (2000) Shiftwork and health. Occupational and Environmental Medicine 27 (4), 10571077 .

Setterlind S. \& Larsson G. (1995) The stress profile: a psychosocial approach to measuring stress. Stress Medicine 11, 85-92.

Spurgeon A. \& Cooper C.L. (2000) Working time, health and performance. In International Review of Industrial and Organizational Psychology, Vol. 15 (C.L. Cooper \& I.T. Robertson eds), pp. 189-222. Wiley \& Sons Ltd, Oxford, UK.

Spurgeon A., Harrington J.M. \& Cooper C.L. (1997) Health and safety problems associated with long working hours: a review of the current position. Occupational and Environmental Medicine $54,367-375$.

Stevens G., Faragher B. \& Sparks K. (2000) The Relationship between Working Hours and Health in an International Sample of Managers. Occupational Psychology Conference, 5-7 January 2000: Book of Proceedings. The British Psychological Society, Leicester, UK.

Weinberg A., Cooper C.L. \& Weinberg A. (1999) Workload, stress and family life in British Members of Parliament and the psychological impact of reforms to their working hours. Stress Medicine 15 (2), 79-87.

Wilson J. (2002) The impact of shift patterns on healthcare professionals. Journal of Nursing Management 10, 211-219. 
Table 1

Time 1 and time 2 comparisons between control and intervention group mean values

\begin{tabular}{|c|c|c|c|}
\hline & Control & Intervention & ANOVA \\
\hline Characteristic & Mean $(S D)$ & Mean $(S D)$ & F-ratio (df) \\
\hline \multicolumn{4}{|c|}{ Work-life balance } \\
\hline T1 & $3.10(1.27)$ & $3.11(1.10)$ & \multirow[t]{2}{*}{$1.88^{* *}(173)$} \\
\hline T2 & $3.00(1.12)$ & $3.39(1.09)$ & \\
\hline \multicolumn{4}{|c|}{ Self-rated health } \\
\hline T1 & $60.33(20.12)$ & $58.48(16.56)$ & \multirow[t]{2}{*}{$0.34(176)$} \\
\hline T2 & $58.82(29.01)$ & $60.07(23.04)$ & \\
\hline \multicolumn{4}{|l|}{ Satisfaction } \\
\hline T1 & $68.00(13.05)$ & $59.24(15.01)$ & \multirow[t]{2}{*}{$3.18^{* *}(175)$} \\
\hline T2 & $62.00(9.16)$ & $62.00(16.15)$ & \\
\hline \multicolumn{4}{|c|}{ Behavioural symptoms } \\
\hline T1 & $20.01(15.64)$ & $21.93(18.01)$ & \multirow[t]{2}{*}{$0.95(174)$} \\
\hline T2 & $23.34(15.66)$ & $20.01(16.43)$ & \\
\hline \multicolumn{4}{|c|}{ Cognitive symptoms } \\
\hline T1 & $26.48(16.63)$ & $27.04(15.03)$ & \multirow[t]{2}{*}{$0.99(174)$} \\
\hline T2 & $30.06(16.88)$ & $29.54(20.03)$ & \\
\hline \multicolumn{4}{|c|}{ Somatic symptoms } \\
\hline T1 & $34.75(10.81)$ & $33.53(13.33)$ & \multirow[t]{2}{*}{$1.25(175)$} \\
\hline T2 & $38.45(10.75)$ & $34.33(13.65)$ & \\
\hline \multicolumn{4}{|l|}{ Vitality } \\
\hline T1 & $63.50(16.23)$ & $54.47(15.90)$ & \multirow[t]{2}{*}{$1.72(174)$} \\
\hline T2 & $57.36(17.36)$ & 56.67 & \\
\hline \multicolumn{4}{|l|}{ Social support } \\
\hline T1 & $70.53(16.60)$ & $69.98(14.30)$ & \multirow[t]{2}{*}{$4.05^{* * *}(174)$} \\
\hline T2 & 70.33 (15.13) & $73.85(21.38)$ & \\
\hline \multicolumn{4}{|l|}{ Community } \\
\hline T1 & $75.40(14.81)$ & $76.48(14.11)$ & \multirow[t]{2}{*}{$4.44^{* * *}(176)$} \\
\hline T2 & 70.79 (15.15) & $84.86(14.06)$ & \\
\hline
\end{tabular}

${ }^{*} P<0.05,{ }^{* *} P<0.01,{ }^{* * *} P=0.001$. 
Table 2

Guidance for those implementing open-rota systems

Key points to consider at implementation

Adopt a team-based approach in which all team members are

involved in the decision to take up the open-rota

Brief all team members to ensure a balance between individual, team and department objectives are maintained

Bring in an objective (independent) facilitator, especially in the early stages of the implementation, to help minimize conflicting objectives between team members and team leaders

Draw on strengths and develop others; some nurses found it difficult at first to manage the detailed finalizing stage of the rota. Attention should be paid to developing employee skills to take on responsibilities

Manage internal competition for preferred dates by setting clear rules and working practices

Allocate the responsibility for fine-tuning rota to one or two individuals; this can be done on a rotating basis

Draw upon past experience: sharing experiences of other areas who have implemented similar interventions can be a useful platform for formulating ideas and gaining buy-in

Conduct frequent reviews to monitor the effectiveness and satisfaction with the system. This can help to fine-tune the system and maintain the momentum of the project

Benefits

No resources other than discussion time are required by the organization

Nursing staff can develop skills in scheduling and time management

Employees gain greater control and predictability over work schedule

Enhanced cooperation and community feel throughout the team Improved job satisfaction and work-life balance reported by

employees

Increased understanding of organizational issues, e.g. availability and allocation of resources

Potential pitfalls

Competition between employees to gain preferred dates

Some employees may be unequipped with the skills to finalize/fine-tune schedule and therefore need coaching and support

Effectiveness can be compromised where the whole team is not signed up to a joint agenda 